\title{
Enterovirus A71 Proteins: Structure and Function
}

\author{
Jingjing Yuan ${ }^{1,2}$, Li Shen $^{3}$, Jing $W u^{4}$, Xinran Zou ${ }^{4}$, Jiaqi Gu ${ }^{4}$, Jianguo Chen ${ }^{1}$ and \\ Lingxiang Mao ${ }^{1 *}$ \\ ${ }^{1}$ Department of Laboratory Medicine, The Affiliated People's Hospital, Jiangsu University, Zhenijang, China, ${ }^{2}$ Clinical \\ Laboratory, Danyang People's Hospital, Jiangsu, China, ${ }^{3}$ Clinical Laboratory, Zhenjiang Center for Disease Control and \\ Prevention, Jiangsu, China, ${ }^{4}$ Institute of Laboratory Medicine, School of Medicine, Jiangsu University, Zhenjiang, China
}

OPEN ACCESS

Edited by:

Encarna Martinez-Salas, Centro de Biología Molecular Severo Ochoa (CSIC), Spain

Reviewed by:

Teresa de los Santos, Agricultural Research Service (USDA), United States

Miguel A. Martín-Acebes, Instituto Nacional de Investigación y Tecnología Agraria y Alimentaria (INIA),

Spain

*Correspondence: Lingxiang Mao maolingxiang@aliyun.com

Specialty section:

This article was submitted to

Virology,

a section of the journal

Frontiers in Microbiology

Received: 11 December 2017 Accepted: 07 February 2018 Published: 21 February 2018

Citation:

Yuan J, Shen L, Wu J, Zou X, Gu J, Chen $J$ and Mao L (2018) Enterovirus A71 Proteins: Structure and Function.

Front. Microbiol. 9:286. doi: 10.3389/fmicb.2018.00286
Enterovirus A71 (EV-A71) infection has grown to become a serious threat to global public health. It is one of the major causes of hand, foot, and mouth disease (HFMD) in infants and young children. EV-A71 can also infect the central nervous system (CNS) and induce diverse neurological complications, such as brainstem encephalitis, aseptic meningitis, and acute flaccid paralysis, or even death. Viral proteins play a crucial role in EV-A71 infection. Many recent studies have discussed the structure and function of EV-A71 proteins, and the findings reported will definitely aid the development of vaccines and therapeutic approaches. This article reviews the progress in the research on the structure and function of EV-A71 proteins. Available literature can provide a basis for studying the pathogenesis of EV-A71 infection in detail.

Keywords: enterovirus-A71, protein, structure, function, epitope

\section{INTRODUCTION}

EV-A71 is one of the major etiological agents causing hand, foot, and mouth disease (HFMD), which generally affects children aged five and below. In addition to HFMD, EV-A71 can cause various neurological complications, including aseptic meningitis, brainstem encephalitis, acute flaccid paralysis, neurogenic pulmonary edema, delayed neurodevelopment, and reduced cognitive function (Ooi et al., 2010). In fact, severe pediatric complications involving the central nervous system (CNS) can even cause death. EV-A71 was first isolated in 1969 from the stool samples of children with CNS-related complications, in California, USA (Schmidt et al., 1974). Since then, several outbreaks have been reported worldwide. For example, an outbreak of EV-A71 caused 29 deaths in Sarawak, Malaysia, in 1997 (Chan et al., 2000). Following that, a large outbreak in Taiwan involved over 100,000 cases, which led to 78 fatalities (Ho et al., 1999). HFMD caused by EV-A71 infection was prevalent in many provinces and cities of mainland China during 2008-2009; it caused the death of 479 children (Sun et al., 2011; Zhang et al., 2011). From 2009 to 2016, the incidence of HFMD caused by EV-A71 in mainland China was on the higher side (Tan et al., 2011). EV-A71 epidemic has resulted in many fatalities because of serious neurological complications, and has since been identified as a serious threat to public health.

EV-A71 belongs to the Picornaviridae family, genus Enterovirus, species Enterovirus A. The EV-A71 particle is non-enveloped, symmetrical, with a $20-30 \mathrm{~nm}$ icosahedral capsid. The viral genome is $\sim 7,500$-nucleotide-long, in the form of a single-stranded positive-sense RNA with only one open reading frame (ORF), flanked by a highly structured $5^{\prime}$-untranslated region $\left(5^{\prime} \mathrm{UTR}\right)$ and a $3^{\prime}$ UTR with a poly(A) tail. The structure of EV-A71 genome is shown in Figure 1. The ORF encodes a single large polyprotein of $\sim 2,100$ amino acids. The polyprotein is further hydrolyzed to form three precursor proteins, namely, P1, P2, and P3. P1 precursor protein is degraded into four 


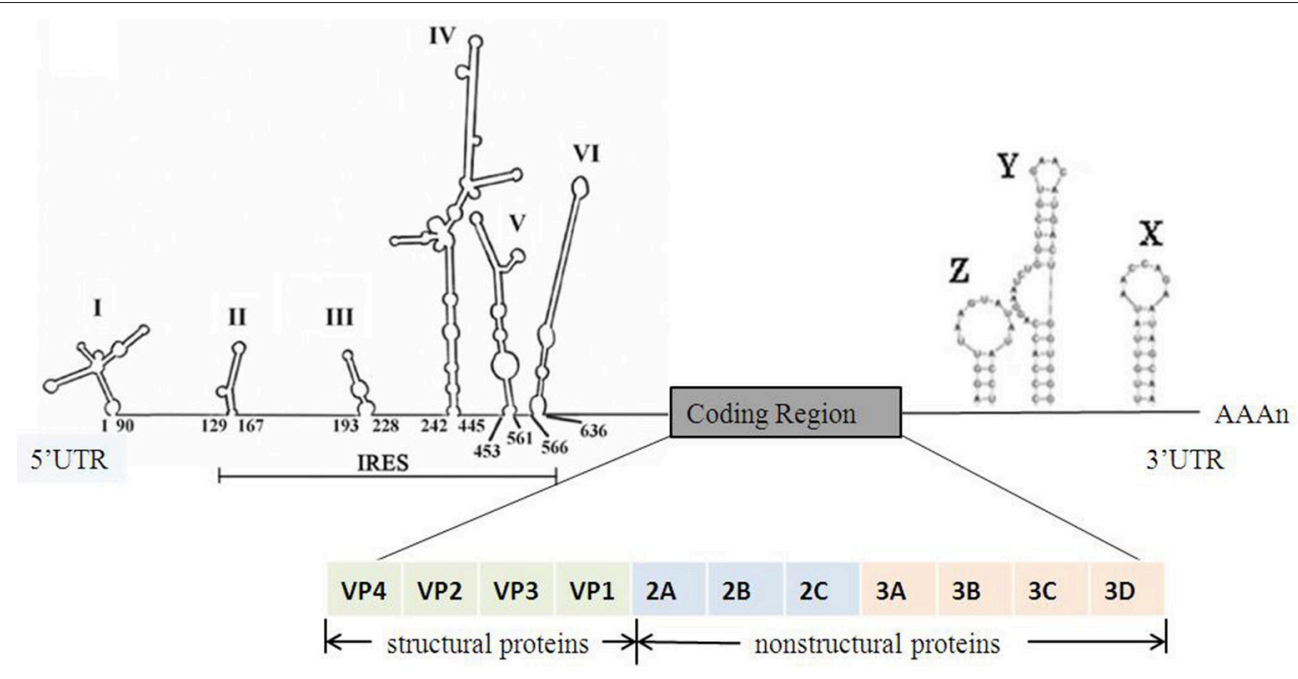

FIGURE 1 | The structure of the EV-A71 genome. The 5'UTR of EV-A71 contains six stem-loop structures (I-VI) (Lin et al., 2009a). Stem loop I functions in negative strand synthesis, whereas stem loops II-VI form the type I IRES element. The ORF encodes a polyprotein which is cleaved into 11 viral proteins including 4 structural proteins and 7 non-structural proteins. The $3^{\prime} U T R$ of EV-A71 contains three stem-loop structures (X, Y, and Z) which are associated with viral RNA replication (Kok et al., 2012).

structural viral proteins, including VP1, VP2, VP3, and VP4. These four proteins assemble to form a protomer. Five such protomers constitute a pentamer, and 12 pentamers together form a virion enclosing the viral genome. VP1, VP2, and VP3 are exposed on the capsid surface, while VP4 is present inside the capsid. The structure of the virion is shown in Figure 2 (Yi et al., 2017). P2 and P3 encode seven non-structural proteins (P2-2A, 2B, 2C; P3-3A, 3B, 3C, 3D) (Solomon et al., 2010). The $5^{\prime}$ UTR of EV-A71 contains six stem-loop structures (I-VI) (Thompson and Sarnow, 2003; Lin et al., 2009b). Stem-loop I is involved in viral RNA synthesis (Tu et al., 2007). Stem-loops IIVI comprise the internal ribosome entry site (IRES), which allows viral protein translation to occur in a cap-independent manner (Thompson and Sarnow, 2003). IRES can be positively regulated by the extracellular signal-regulated kinase $1 / 2$ (ERK1/2), which is essential for the efficient replication of EV-A71 (Wang B. et al., 2012; Gao et al., 2014; Zhu et al., 2015). In addition, IRES binds to the cellular factor $68-\mathrm{kDa}$ Src-associated protein during mitosis (Sam68), and the early growth response-1 (EGR1) facilitates EVA71 replication (Song et al., 2015; Zhang et al., 2015). EV-A71 genome replication and RNA translation can be clearly inhibited when the cloverleaf structure and IRES are infected by sirtuin 1 (SIRT1) (Han et al., 2016). Thus, $5^{\prime}$ UTR is essential for regulating EV-A71 replication and it is a potential drug target for treating EV-A71 infection. The 3'UTR of EV-A71 is a highly conserved domain, which contains three putative stem-loop structures (X, $\mathrm{Y}$, and Z), followed by a poly(A) tail. Sequence analysis showed that $\mathrm{X}$ is the most conserved region, and $\mathrm{Z}$, the least conserved, between the subgenogroups (Kok et al., 2012). Wang et al. proved that the point mutations introduced in $3^{\prime}$ UTR to destabilize the kissing interaction, which is required for the maintenance of the overall structure of the enteroviral $3^{\prime} \mathrm{UTR}$, resulted in a lethal phenotype. Therefore, the $3^{\prime}$ UTR seems to play an important role in viral replication (Wang et al., 1999; Kok et al., 2012).

Individuals are infected with EV-A71 through the alimentary tract. The murine model showed that EV-A71 first replicates in the tonsils and lymph nodes, and subsequently goes through to the peripheral lymph node, leading to viremia. Then, the virus binds with specific receptors to initiate EV-A71 infection and intracellular replication (Chen et al., 2004). EV-A71 has several specific receptors: human P-selectin glycoprotein ligand 1 (PSGL-1), scavenger receptor B2 (SCARB2), human annexin II protein, sialylated glycan, and heparan sulfate. Compared to others, SCARB2 is considered the primary receptor of EV-A71 (Nishimura et al., 2009; Yamayoshi et al., 2009; Yang et al., 2009, 2011; Tan et al., 2013). EV-A71 enters host cells through specific receptors. At the same time, the polysaccharide and sialic acid on the cell surface play an important role in virus adsorption. Studies have found that the polysaccharide and sialic acid on the cell surface can be instrumental in allowing large number of viruses to enter the cells ( $\mathrm{Su}$ et al., 2012). After binding to the viral receptors and entering the host cell via receptormediated endocytosis, the EV-A71 genome is translated in a cap-independent manner into a large polyprotein (Thompson and Sarnow, 2003), which is subsequently processed by the viral proteases $2 \mathrm{~A}^{\text {pro }}$ and $3 \mathrm{C}^{\text {pro }}$ to form the structural capsid proteins (VP1-VP4) and the non-structural proteins (2A-2C, 3A-3D). The non-structural proteins are predominantly involved in the replication and translation of viral RNA (Bedard and Semler, 2004; Lin et al., 2009a). The parent RNA is used as the template for viral replication. During the replication of the whole virus, the genomic RNA directs the synthesis of the viral polyprotein, followed by the assembly and release of infectious virions. Studies on other picornaviruses have showed that translation and RNA replication cannot occur simultaneously on the same RNA 

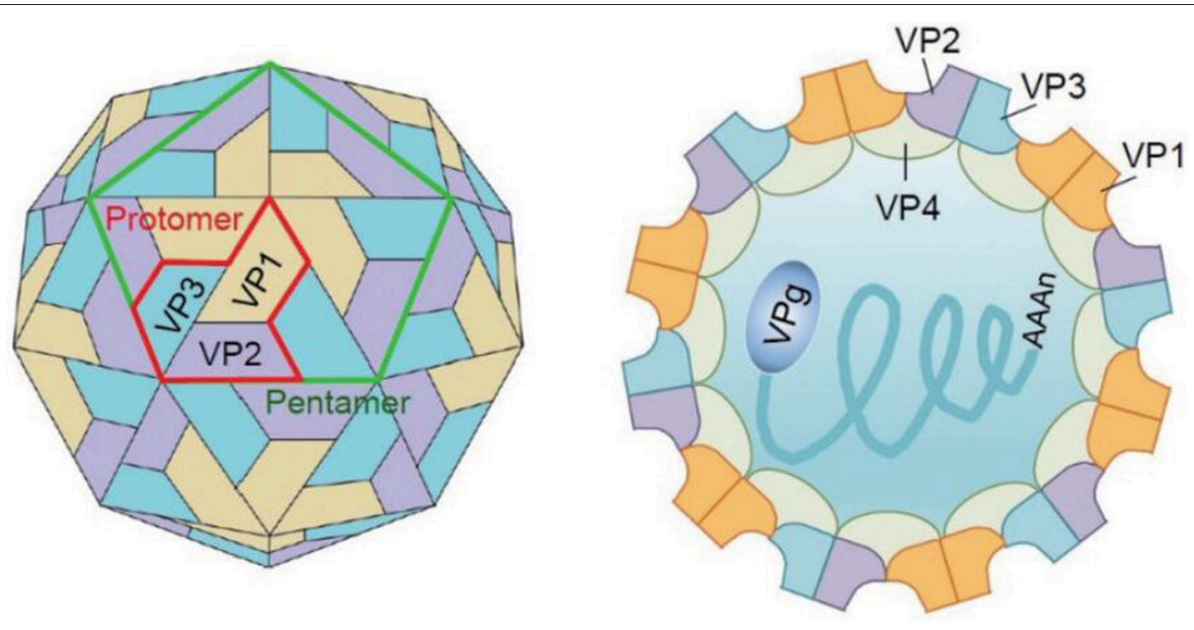

FIGURE 2 | The structure of the virion. Three viral structural proteins (VP1-VP4) function as a single structural subunit, the protomer. Five protomers then form a pentamer, twelve of which can self-associate to form a capsid enclosing the viral genome. VP1, VP2, and VP3 are external of the virion, whereas VP4 is completely internalized in the virion (Yi et al., 2017).

molecule, indicating that there is a molecular switch to shut down RNA replication and allow initiation of translation (Wimmer et al., 1987; Shih et al., 2011). A comprehensive understanding of the structure and function of viral proteins will greatly help further the knowledge about the pathogenesis of EV-A71 as well as the strategies to resist EV-A71.

\section{Structural Proteins}

As mentioned earlier, the icosahedral capsid of EV-A71 consists of 60 identical protomers, each containing four different structural proteins (VP1-VP4). This viral capsid encloses single-stranded positive-sense RNA. During assembly, the P1 polyprotein is cleaved to VP0 $(36 \mathrm{kDa}), \mathrm{VP} 1(32 \mathrm{kDa})$, and VP3 $(27 \mathrm{kDa})$, and VP0 is subsequently cleaved into VP2 $(28 \mathrm{kDa})$ and VP4 (8 kDa). VP1-VP3 are exposed on the capsid surface and span the thickness of the capsid, while VP4 is located inside the capsid (Plevka et al., 2012).

\section{VP1 Protein}

VP1 is a capsid protein consisting of 297 amino acids. According to the crystal structure, VP1 is the most external part and the primary protein constituting two important structures: "canyon" and "pocket factor." The depression around the icosahedral five-fold axes is called the "canyon" (Plevka et al., 2012). The hydrophobic "pocket factor" is mainly exposed on the surface of the canyon. The "pocket factor" can stabilize the virion. After EVA71 infects the cell, VP1 binds with specific receptors (including PSGL-1 and SCARB2) (Nishimura et al., 2009; Yamayoshi et al., 2009; Yang et al., 2009, 2011; Tan et al., 2013), which have an immunoglobulin-like fold in the canyon. This immediately causes the expulsion of the hydrophobic "pocket factor" from the base of the "canyon," leading to the destabilization of EVA71. The destabilization is likely to be a prelude to genome release (Rossmann, 1994; Rossmann et al., 2002; Plevka et al., 2012). Receptor binding needs VP1-145 as a switch, which controls PSGL-1 binding by modulating the exposure of VP1$244 \mathrm{~K}$ (Nishimura et al., 2013). Upon binding to the receptor(s), the EV-A71 virions undergo a two-step uncoating process, first conforming into an expanded, altered "A-particle," which expels VP4 and exposes the N-terminus of VP1, subsequently anchoring the amphipathic helices into the membrane. Second, the EV-A71 A-particle capsid opens a two-fold channel near the icosahedral two-fold axis of symmetry to allow genome release, and forms a pore in the endosomal membrane to allow the genome to pass into the cytosol (Shingler et al., 2013). Additionally, the crystal structure of the EV-A71 uncoating intermediate showed that the N-terminal extensions of VP1 (residues 1-71) interact with the viral RNA (Lyu et al., 2014). Mutations in the VP1 Nter residues can increase cell tropism, which contributes to the pathogenesis of EV-A71 infection. The change in VP1 $(244 \mathrm{~K} \rightarrow \mathrm{E})$ of a sub-genogroup B5 strain or VP1 $(145 \mathrm{Q} \rightarrow \mathrm{E})$ of a subgenogroup $\mathrm{C} 4$ strain is the critical genetic determinant of mouse adaptation and virulence (Zaini and McMinn, 2012; Zaini et al., 2012). Moreover, VP1-145E variants are mainly responsible for the development of viremia and neuropathogenesis in a nonhuman primate model (Kataoka et al., 2015). In addition, VP1activated endoplasmic reticulum (ER) stress and autophagy could promote the upregulation of Ecto-CRT (cell surface-exposed calreticulin), which is an important mediator for primary phagocytosis of viable neurons by the microglia ( $\mathrm{Hu}$ et al., 2017).

VP1 has six surface loops (BC, DE, BE/aB, GF, GH, and $\mathrm{HI}$ ), which are located around the icosahedral five-fold axes. The loops exposed on the virion surface are the most variable regions of EV-A71. The VP1 $(97 \mathrm{~L} \rightarrow \mathrm{R})$ substitution within the BC loop clearly increased neural cell tropism (Cordey et al., 2012). Ku et al. found that three neutralizing monoclonal antibodies bound the same conserved epitope located at the VP1 GH loop of EV-A71. Further, these monoclonal antibodies can inhibit both viral attachment and internalization during viral entry (Ku et al., 
2015). Several studies showed that there is a neutralizing epitope close to the VP1 GH loop (Foo et al., 2007; Liu et al., 2011; Xu et al., 2015). In particular, this peptide (overlapping with the GH loop) lies on the capsid surface alongside the VP2 EF loop (residues 136-150) to form a functionally important epitope. Based on this, several monoclonal antibody $(\mathrm{mAb})$ candidates with therapeutic potential were identified, such as mAb 2G8 (Deng et al., 2015), mAb51 (Lim et al., 2013), and mAb 22A12 (Shingler et al., 2015). The major epitopes in the structural proteins are shown in Table 1. Considering that EV-A71 VP1 is highly conserved and has many epitopes, most studies have focused on developing recombinant VP1 vaccines. Compared to inactivated vaccines, these are safer and more cost-effective. This showed the potential of recombinant VP1 vaccines as good vaccine candidates (Kiener et al., 2013; Yu et al., 2013; Xu and Zhang, 2016).

In addition, the VP1 gene is serotype-specific and considered as the most suitable region for sequence analysis (Wu J. S. et al., 2013; Wu W. H. et al., 2013; Duy et al., 2017). EVA71 can be divided into three distinct genogroups (A, B, and C) (Brown et al., 1999). Genogroups B and C can be further divided into genogroups B1-B5 and C1-C5 (Solomon et al., 2010). A phylogenetic tree constructed for EV-A71 strains of all genotypes/subgenotypes based on the complete sequence of the VP1-coding gene is shown in Figure 3.

\section{VP2-VP3 Protein}

VP2, VP3, and VP1 have the same topology: they form an eightstranded anti-parallel $\beta$-barrel structure in the form of a wedge that facilitates packing. The form looks like $\beta$-sandwich "jellyroll” folds. The main structural differences are the connecting loops and the C-termini on the outer side of the capsid (Kiener et al., 2012). In VP2, the most prominent surface loop is the "puff," and in VP3, the largest protrusion on the surface is the "knob" (Plevka et al., 2012).

VP2 consists of 254 amino acids. VP2 has several neutralization epitopes, just as VP1 (Table 1). The epitopemapping experiment showed a highly conserved linear epitope, namely, the residues 136-150 of VP2, which are highly conserved among the EV-A71 genotypes. VP2 ${ }_{136-150}$ is not affected by formalin treatment and long-term storage, which makes it a surrogate biomarker in the potency testing of candidate EV-A71 vaccines (Liu et al., 2011). Xu et al. reported that there is a cross-neutralizing linear epitope, spanning amino acids 141-155, which lies in the large and highly variable surface loop of VP2 (Xu et al., 2014). Kiener et al. also showed a single, linear, non-neutralizing epitope, spanning amino acids 142-146, located in the EF loop of EV-A71 VP2. The S/T (144) mutation in this epitope confers loss of VP2 antigenicity to some new EV-A71-C4 strains from China (Kiener et al., 2012). A mutant virus with lysine to methionine substitution at VP2 149 (VP2$149 \mathrm{M})$ or glutamine to glutamic acid substitution at VP1-145 (VP1-145E) showed higher viral titers and increased apoptosis. The synergistic effect of VP2-149M and VP1-145E double mutations enhanced viral binding and accumulation of EV-A71 RNA, contributing to viral infectivity in vitro and mouse lethality in vivo (Huang et al., 2012).

VP3 consists of 245 amino acids, among which the amino acids 59-67 of VP3 are more highly conserved between the subgenogroups, compared to VP1. There is a conserved conformational epitope on the "Knob" region of VP3, which makes it an ideal target for a diagnostic or therapeutic mAb. The $\mathrm{mAb}$ 10D3 can generally recognize this conservative epitope, not coxsackievirus A16 (CVA16), which makes mAb 10D3 a valuable

TABLE 1 | Major epitopes in structural proteins.

\begin{tabular}{|c|c|c|c|c|c|c|}
\hline Region & Location & Name & $\begin{array}{l}\text { Amino acid } \\
\text { position }\end{array}$ & Peptide sequences & $\begin{array}{l}\text { Characteristics of the } \\
\text { epitope }\end{array}$ & References \\
\hline \multirow[t]{9}{*}{ VP1 } & \multirow[t]{3}{*}{ Neighboring location } & PEP27 & $142-156$ & PTGEWPQLLQYMFV & $\begin{array}{l}\text { EV-A71-specific lgM } \\
\text { epitope }\end{array}$ & Aw-Yong et al., 2016 \\
\hline & & SP2 & $145-159$ & EVVPQLLQYMFVPPG & CD4+ T-cell epitopes & Foo et al., 2008 \\
\hline & & VP1-20 & $145-162$ & EVVPQLLQYMFVPPGAPK & CD4+ T-cell epitopes & Tan et al., 2013 \\
\hline & \multirow[t]{3}{*}{ Neighboring location } & PEP23 & $41-55$ & TGEVPALQAAEIGAS & IgG epitope & Aw-Yong et al., 2016 \\
\hline & & VP1-15 & $43-54$ & KVPALQAAEIGA & IgG epitope & Gao et al., 2012 \\
\hline & & vp1-14 & $40-51$ & DTGKVPALQAAE & Anti-EV71 IgM epitope & Gao et al., 2012 \\
\hline & \multirow{3}{*}{$\begin{array}{l}\text { Neighboring location } \\
\text { (close to the VP1 } \\
\text { GH loop) }\end{array}$} & VP1-43 & $211-220$ & FGEHKQEKDL & Neutralization epitope & Liu et al., 2011 \\
\hline & & SP70 & $208-222$ & YPTFGEHKQEKDLEYC & Neutralizing linear epitope & Foo et al., 2007 \\
\hline & & VP1(aa208-222) & $208-222$ & YPTFGEHKQEKDLEYC & Neutralizing linear epitope & Xu et al., 2015 \\
\hline \multirow[t]{5}{*}{ VP2 } & \multirow{5}{*}{$\begin{array}{l}\text { Neighboring location } \\
\text { (close to VP2 EF } \\
\text { loop ) }\end{array}$} & VP2-28 & $136-150$ & AGGTGTEDSHPPYKQ & Neutralization epitope & Liu et al., 2011 \\
\hline & & $\begin{array}{l}\text { VP2(aa141-155s) } \\
\text { 7C7 }\end{array}$ & $\begin{array}{l}141-155 \\
142-146\end{array}$ & $\begin{array}{l}\text { TEDSHPPYKQTQPGA } \\
\text { ED/NSHP }\end{array}$ & $\begin{array}{l}\text { Neutralization epitope A } \\
\text { linear, non-neutralizing } \\
\text { epitope }\end{array}$ & $\begin{array}{l}\text { Kiener et al., 2012; } \\
\text { Xu et al., } 2014\end{array}$ \\
\hline & & PEP10 & $134-148$ & TVAGGTGTEDSHPPY & Neutralization epitope & Aw-Yong et al., 2016 \\
\hline & & VP2-24 & $176-193$ & TVCPHQWINLRTNNCATI & T cell epitope & Tan et al., 2013 \\
\hline & & A3 & $248-263$ & PHQWINLRTNNCATII & CD4+ T Cell Epitop & Wei et al., 2012 \\
\hline VP4 & & VP4N20 & $\begin{array}{l}\text { first } 20 \\
\text { amino acids }\end{array}$ & GSGVSTGASGSHGASASATG & Neutralization epitope & Zhao et al., 2013 \\
\hline
\end{tabular}




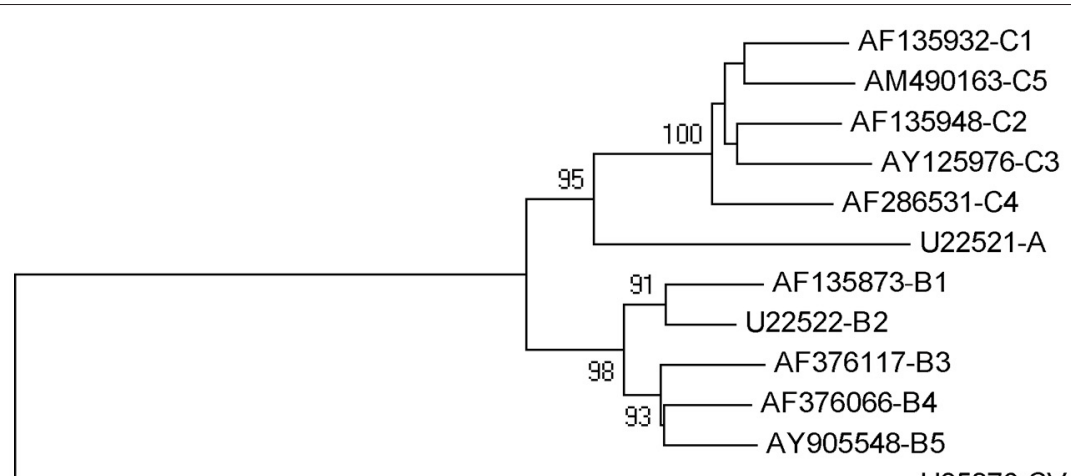

U05876-CVA16-G10

\section{$\stackrel{102}{\longmapsto}$}

FIGURE 3 | Phylogenetic tree constructed among EV71 strains of all genotype/ subgenotype based on complete sequence of vp1 coding gene. Note:bootstrap value (percentage of 1,000 pseudoreplicate datasets) supporting each cluster are shown at the node. Phylogenetic and molecular evolutionary analyses were conducted using MEGA version 5.0.

tool for differential diagnosis (Kiener et al., 2014). Recently, a therapeutic IgG antibody, $5 \mathrm{H} 7$, was confirmed to recognize a conformational epitope, which was mapped to the highly conserved amino acid position 74 of VP3 (Jia et al., 2017).

\section{VP4 Protein}

VP4 consists of 69 amino acids. VP4 has an extended conformation and is present inside the virion. It is myristylated and confers stability to the capsid (Chow et al., 1987). VP4 gene is more conserved than VP1, VP2, and VP3 genes, and therefore, some studies on the EV-A71 vaccine focused on whether the VP4 protein contains neutralizing epitopes. The study further identified a highly conserved linear neutralizing epitope in the $\mathrm{N}$-terminus of EV-A71 VP4 by epitope-mapping experiments. In the present study, the peptide containing $\mathrm{N}$-terminal residues 1-20 of EV-A71 VP4 of the genotype C4 was fused to hepatitis B core antigen $(\mathrm{HBcAg})$ and expressed in Escherichia coli. This fusion protein was able to spontaneously assemble into chimeric virus-like particles (VLPs), which elicited a virus-neutralizing antibody response. The results suggest that chimeric $\mathrm{HBcAg}$ particles carrying a neutralizing epitope of EV-A71 VP4 can be a promising vaccine candidate against EV-A71 infection (Zhao et al., 2013). As mentioned earlier, during viral uncoating, after the formation of the "A-particle," the VP4 proteins are expelled and inserted into the membrane to form a channel through which the RNA can enter the host cell cytoplasm (Shingler et al., 2013). VP4 gene was also thought to be suitable for sequence analysis of EV-A71, just like VP1 (Chu et al., 2001; Ishiko et al., 2002; Shimizu et al., 2004).

The primary functions of EV-A71 structural proteins are shown in Table 2.

\section{Non-structural Proteins 2A Protein}

EV-A71 $2 \mathrm{~A}$ proteinase $\left(2 \mathrm{~A}^{\text {pro }}\right)$ is a cysteine proteinase and contains $\sim 150$ amino acids. According to the crystal structure,
TABLE 2 | The functions of EV-A71 structural proteins.

\begin{tabular}{lll}
\hline Protein & Functions & References \\
\hline VP1 & Receptor binding epitopes & $\begin{array}{l}\text { Nishimura et al., 2009; } \\
\text { Yamayoshi et al., 2009; Yang } \\
\text { et al., 2009, 2011; Tan et al., } \\
\end{array}$ \\
& 2013 \\
& Increase cell tropism & Cordey et al., 2012; Zaini et al., \\
& Regulate EV-A71 maturation & 2012; Kataoka et al., 2015 \\
& Zhang et al., 2017 \\
& Wu C. et al., 2013; Wu J. S. \\
& Potency test biomarker of & Liu et al., 2011 \\
VP2 & candidate EV-A71 vaccines & \\
& Epitopes & \\
VP3 & mAb target & Kiener et al., 2014 \\
& Therapeutic antibody target & Jia et al., 2017 \\
VP4 & Epitopes & \\
\hline
\end{tabular}

$2 \mathrm{~A}^{\text {pro }}$ maintains a chymotrypsin-like fold. The active site is composed of the catalytic triads, namely, C110A, H21, and D39. Moreover, $2 \mathrm{~A}^{\text {pro }}$ contains a tightly folded cI-to-eI2 loop at the $\mathrm{N}$-terminal domain and renders a hydrophilic surface for host protein recognition. At the C-terminal of $2 \mathrm{~A}^{\text {pro }}$, there is an important structure composed of a hydrophobic motif "LLWL," followed by an acidic motif "DEE." The "LLWL" motif is folded into a previously unknown double $\beta$-turn structure, which is essential for the positioning of the acidic motif. The acidic motif and the preceding "LLWL" motif at the C-terminus of $2 \mathrm{~A}^{\text {pro }}$ are essential for viral replication (Mu et al., 2013).

The protease activity of $2 \mathrm{~A}^{\text {pro }}$ deems $2 \mathrm{~A}^{\text {pro }}$ important in viral replication, apoptosis, pathogenesis, and other processes. First, $2 \mathrm{~A}^{\text {pro }}$ is responsible for shearing the synthesized poly-proteins. $2 \mathrm{~A}^{\text {pro }}$ theoretically catalyzes the peptide bond cleavage between VP1 (C-terminal) and P2 (N-terminal of 2A protein). 2A $\mathrm{Aro}^{\text {pro }}$ can 
also cleave $3 \mathrm{CD}$ to produce $3 \mathrm{C}^{\prime}$ and $3 \mathrm{D}^{\prime}$. In addition, $2 \mathrm{~A}^{\text {pro }}$ exhibited strong transcriptional activity in yeast cells, which was independent of its protease activity. The transcriptional activity of EV-A71 $2 \mathrm{~A}^{\text {pro }}$ plays a role in viral replication and/or pathogenesis (Yang et al., 2010). Li et al. demonstrated that $2 \mathrm{~A}^{\text {pro }}$ modulates the replication and virulence of EV-A71 by testing the virulence of $2 \mathrm{~A}^{\text {pro }}$-replaced chimeric strains ( $\mathrm{Li} \mathrm{C}$. et al., 2017). As mentioned earlier, ERK is crucially involved in the positive regulation of EV-A71 IRES. Duan et al. demonstrated that the positive regulation of viral replication by the ERK cascade was mediated by affecting both cis-cleavage of the viral polyprotein by $2 \mathrm{~A}^{\text {pro }}$ and trans-cleavage of the cellular eIF4GI (Duan et al., 2017). Additionally, Wu et al. observed that the expression of EV-A71 2A pro alone was sufficient to cause stress granule formation ( $\mathrm{Wu}$ et al., 2014). 2A $\mathrm{A}^{\text {pro }}$ cleaves the host translation initiation factor, the eukaryotic translation initiation factor 4-gamma 1(eIF4G1), to induce apoptosis (Kuo et al., 2002).

$2 \mathrm{~A}^{\text {pro }}$ uses some mechanisms to escape innate immunity. $2 \mathrm{~A}^{\text {pro }}$ and $3 \mathrm{C}^{\text {pro }}$ cleave NLRP3 (NOD-like receptor family, pyrin domain containing 3) protein, which plays a protective role against EV-A71 infection, leading to EV-A71 counteracting inflammasome activation (Wang $H$. et al., 2015). 2A pro contributes to the evasion of innate immunity by cleaving Type I interferon (IFN)- $\alpha / \beta$ receptor 1 (IFNAR1) to block IFN-induced Jak/STAT signaling (Liu et al., 2005; Yi et al., 2011). This makes $2 \mathrm{~A}^{\text {pro }}$ a potential drug target for antiEV-A71-infection activities. CW-33 combined with a low-dose of Type I IFN can be used to treat EV-A71 infection by inhibiting $2 \mathrm{~A}^{\text {pro }}$ activity (Wang C.Y. et al., 2015). 2A $\mathrm{A}^{\text {pro }}$ is able to cleave the nuclear pore glycoprotein protein 62 (Nup62), disrupting host nuclear transport pathways and altering nuclear permeability (Zhang et al., 2013). 2A $\mathrm{A}^{\text {pro }}$ can specifically slice mitochondrial antiviral signaling (MAVS) protein, inactivating the antiviral innate immune response of retinoic acid-induced gene-I (RIG-I) and melanoma differentiation-associated gene, thereby lowering the production of Type I IFN (Wang et al., 2013). In addition, Wang et al. showed that $2 \mathrm{~A}^{\text {pro }}$ attenuated IFN- $\gamma$ signaling by reducing serine phosphorylation of signal transducers and activators of transcription 1 (STAT1), after the inactivation of extracellular signal-regulated kinases without affecting STAT1 expression (Wang L. C. et al., 2015).

\section{B Protein}

EV-A71 2B protein is an ion channel protein and contains $\sim 100$ amino acids. It has two transmembrane domains(TM1 and TM2). Xie et al. demonstrate that EV71 2B protein forms an ion channel and chloride is the principal ion carried in the 2B-mediated current. As a cytolytic virus, EV71 may primarily release its progeny via cell lysis. The 2B-mediated, chloride- dependent current may perturb anion homeostasis in the Golgi complex and ultimately increase virus production. $4,4^{\prime}$-diisothiocyano- $2,2^{\prime}$-stilbenedisulfonic acid (DIDS) can suppress virus release by inhibiting the $2 \mathrm{~B}$ proteinmediated chloridedependent current (Xie et al., 2011).
Cong et al. reported that $2 \mathrm{~B}$ induces cell apoptosis and affects the mitochondrial apoptotic pathway by directly modulating the redistribution and activation of the proapoptotic protein Bax. After EV-A71 infection, 2B protein is localized to the mitochondria. Then, it interacts with and activates Bax to induce cell apoptosis (Cong et al., 2016).

\section{C Protein}

EV-A71 2C protein mainly functions as an NTPase and contains 329 amino acids. It consists of three subdomains: an ATPase domain, a zinc finger, and a long protruding C-terminal $\alpha$ helix (PDB References: 5GRB). Zinc fingers show trigonal bipyramidal geometry, with the zinc-binding site presenting a key difference among picornaviral $2 \mathrm{C}$ homologs. The long protruding $\mathrm{C}$-terminal $\alpha$-helix is proved to be involved in the self-oligomerization of 2C in solution (Guan et al., 2017).

The amino acids located at 5-43 on the N-terminus of $2 \mathrm{C}$ have potential membrane-binding activity. These amino acids are involved in the rearrangement of host cell membrane proteins and formation of viral replication complex. In this process, 2C mainly associates with the ER protein 3 of host cells and combines with the viral double-stranded RNA, thus forming a viral replication complex (Tang et al., 2007). Also, 2C can recruit COPI to the viral replication complex to ensure effective replication of EV-A71 (Wang J. et al., 2012).

$2 \mathrm{C}$ is involved not only in viral replication, but also in innate immune evasion. Du et al. demonstrated that EV-A71 2C can reduce the formation of the predominant form of NF- $\kappa \mathrm{B}$ (heterodimer p65/p50) by interacting with the IPT domain of RelA(p65) (Du et al., 2015). In addition, EV-A71 2C can inhibit IKK $\beta$ activation, thus blocking NF- $\kappa \mathrm{B}$ activation (Zheng et al., 2011). These might be novel mechanisms adopted by EV-A71 to antagonize innate immunity.

\section{A Protein}

EV-A71 $3 \mathrm{~A}$ protein is a membrane-bound protein, containing 86 amino acids. The $\mathrm{N}$-terminus of $3 \mathrm{~A}$ is rich in proline residues and is involved in protein-protein interactions. Like other enteroviruses, EV-A71 relies on phosphatidylinositol-4kinase III $\beta$ (PI4KB) for genome RNA replication. 3A interacts with a host factor acyl-coenzyme A-binding domain-containing 3 (ACBD3) to recruit PI4KB to the genome replication sites, which facilitates viral RNA replication (Xiao et al., 2017). Lei et al. also showed that the Golgi resident protein ACBD3 can facilitate the replication of EV-A71 by interacting with $3 \mathrm{~A}$. The viral and host proteins form a large complex that is necessary for RNA synthesis at replication sites (Lei et al., 2017a). A recent study showed that EV-A71 3A can interact with human $\beta 3$ subunit of $\mathrm{Na}+/ \mathrm{K}+$-ATPase (ATP1B3) protein, which inhibit EV-A71 replication by enhancing the production of type-I IFN. Although the role of $3 \mathrm{~A}$ in this response is not clear, this might be a mechanism by which $3 \mathrm{~A}$ escapes innate immunity ( $\mathrm{Lu}$ et al., 2016). It is worth mentioning that an FDA-approved drug, itraconazole (ITZ), has been identified as an effective inhibitor of EV-A71 replication, in the low-micromolar range, by targeting 3A (Gao et al., 2015). 


\section{B Protein}

EV-A71 3B protein, also known as VPg (virus genome-linked protein), is a nucleic acid chaperone protein and contains $\sim 22$ amino acids. The crystal structure of the EV-A71 3D pol $-\mathrm{VPg}$ complex showed that VPg was anchored at the bottom of the palm domain of the $3 \mathrm{D}^{\text {pol }}$ molecule and exhibited an extended V-shape conformation (Chen et al., 2013).

VPg uridylylation is essential for picornavirus RNA replication. In the context of viral genomic RNA, the mutations that abolished VPg uridylylation activity were lethal for EV-A71 replication (Chen et al., 2013). Sun et al. reported that Site-311, which located at the base of the palm domain of EV-A71 3D pol, is a VPg-binding site that stabilizes the VPg molecule during VPg uridylylation. Their research also suggested a two-molecule model for 3D ${ }^{\text {pol }}$ during EV-A71 VPg uridylylation, such that one $3 \mathrm{D}^{\mathrm{pol}}$ presents the hydroxyl group of the third amino acid Tyr of VPg to the polymerase active site of another $3 \mathrm{D}^{\mathrm{pol}}$, which, in turn, catalyzes $\mathrm{VPg} \rightarrow \mathrm{VPg}$-pU conversion. These results indicate that the VPg uridylylation reaction involves the binding of VPg to $3 \mathrm{D}^{\text {pol }}$ and the transfer of uridine monophosphate (UMP) by $3 \mathrm{D}^{\text {pol }}$ to the hydroxyl group of the third amino acid Tyr of VPg (Sun et al., 2012).

\section{C Protein}

EV-A71 3C protease (3C $\mathrm{C}^{\text {pro }}$ ) is a cysteine protease containing 184 amino acids. Like $2 \mathrm{~A}^{\text {pro }}, 3 \mathrm{C}^{\text {pro }}$ has a typical chymotrypsinlike fold. Cui et al. found an important surface loop, denoted as the $\beta$-ribbon, which adopts a novel open conformation in EV-A71 3C ${ }^{\text {ro }}$. Two important residues, namely, Gly123 and His 133, located at the base of the $\beta$-ribbon form hinges, and the hinge residues are important for the proteolytic activity of EV-A71 3C ${ }^{\text {pro }}$ (Cui et al., 2011). However, Wu et al. reported (PDB References: 4ghq) that the conformation of $\beta$-ribbon was the same as that in all other picornavirus $3 \mathrm{C}^{\text {pro }}$ structures, which constituted an essential part of the substrate-binding cleft, but differed from the one discussed in a previous article but differs from a previous structure in a different space group (Wu C. et al., 2013).

EV-A71 $3 C^{\text {pro }}$ plays an irreplaceable role in segmenting the precursor polyprotein during viral replication. During viral replication, $3 \mathrm{C}^{\text {pro }}$ cuts itself from the $\mathrm{P} 3$ precursor protein, and then cuts P2 and P3 to form viral proteins. Moreover, $3 \mathrm{C}^{\text {pro }}$ was found to possess RNA-binding activity. Mutations in EV-A71 $3 \mathrm{C}^{\text {pro }}$ influenced RNA-binding activity and proteolytic activity

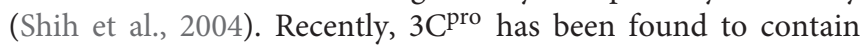
a novel virulence determinant involved in EV-A71 infection. The recombinant virus with a single point variation in the 69th residue of $3 \mathrm{C}^{\text {pro }}$ exhibited an obvious decline in replication and virulence. Thus, the 69 th residue of $3 \mathrm{C}^{\text {pro }}$ has been identified as a novel virulence determinant of EV-A71 (Li B. et al., 2017). $\mathrm{Ma}$ et al. recently confirmed that the polymorphisms of EVA71 $3 C^{\text {pro }}$ at the 79th amino acid position were associated with clinical severity and viral replication, which might be related to the interaction of $3 C^{\text {pro }}$ with important host proteins such as tripartite motif-containing protein 21 (TRIM21) (Ma et al.,

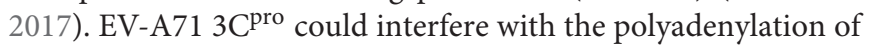

host mRNA by digesting the host protein CstF-64, a cleavagestimulating factor responsible for $3^{\prime}$ pre-mRNA cleavage and polyadenylation (Weng et al., 2009).

EV-A71 $3 C^{\text {pro }}$ plays a critical role in the immune evasion of EV-A71 infection. Transforming growth factor- $\beta$-activated kinase 1 (TAK1) plays a role in the formation of TAK1/TAB1 (TAK1-binding protein1)/TAB2/TAB3 complex. TAK1, TAB1, TAB2, and TAB3 are all essential for downstream NF- $\kappa$ B activation. Lei et al. showed that EV-A71 3C pro suppresses cytokine expression via cleavage of the TAK1/TAB1/TAB2/TAB3 complex. On the other hand, EV-A71 disables the components of TAB2 complex by $3 \mathrm{C}^{\text {pro }}$-mediated cleavage of TAB2 and its partners, while the overexpression of TAB2 inhibits EVA71 replication (Lei et al., 2014). Further, EV-A71 3C ${ }^{\text {pro }}$ can inhibit host immune response by cleaving the adaptor protein TRIF (TIR-domain-containing adapter-inducing interferon$\beta$ ) and IFN regulatory factor 7 (IRF7) (Lei et al., 2010, 2013).

In addition, $3 C^{\text {pro }}$ can regulat cell pyroptosis and apoptosis through different pathways. Lei et al. demonstrated that EV-A71 3Cpro directly cleaves gasdermin D (GSDMD), an important component of pyroptosis, which can regulate lipopolysaccharide and NLRP3-mediated secretion of interleukin-1 $\beta$ (IL-1 $\beta$ ), resulting in inhibiting cell pyroptosis (Lei et al., 2017b). Li et al. used the human glioblastoma SF268 cell line to investigate the induction of apoptosis by EV-A71 3C ${ }^{\text {pro }}$. They found that the proteolytic activity of $3 \mathrm{C}^{\text {pro }}$ triggers apoptosis in the SF268 cells through a mechanism involving caspase activation, and that this apoptotic pathway might play an important role in the pathogenesis of EV-A71 infection (Li et al., 2002). 3C pro also promoted apoptosis by cleaving PinX1 (a telomere-binding protein) using its protease activity, and that this cleavage facilitated EV-A71 release (Li J. et al., 2017). Further, it was reported that SUMOylation (where SUMO is small ubiquitinlike modifier) promotes EV-A71 3C ${ }^{\text {pro }}$ ubiquitination, leading to degradation, correlating with a decrease in viral replication and cell apoptosis. $3 \mathrm{C}^{\text {pro }}$ can be SUMO-modified at the residue Lys 52 by the SUMO E2-conjugating enzyme Ubc9. SUMOylation down-regulated $3 \mathrm{C}^{\text {pro }}$ activity in vitro and $3 \mathrm{C}^{\text {pro }}$ stability in the cells (Chen et al., 2011). Because $3 \mathrm{C}^{\text {pro }}$ is irreplaceable in viral replication, some antiviral drugs are targeted at $3 \mathrm{C}^{\mathrm{pro}}$, such as DC07090 (Ma et al., 2016) and luteoloside (Cao et al., 2016).

\section{D Protein}

EV-A71 3D polymerase (3D ${ }^{\text {pol }}$ ), containing $\sim 462$ amino acid, works as an RNA-dependent RNA polymerase (RdRp). The overall crystal structure of EV-A71 3D pol (PDB References: $3 \mathrm{~N} 6 \mathrm{~L}$ ) adopts the usual closed "right-hand" conformation observed in other RdRps, which is composed of "fingers," "palm" and "thumb" domains. 3D pol has six conserved motifs, each containing four-amino-acid-long sequences, namely, motif A, B, $\mathrm{C}, \mathrm{D}, \mathrm{E}$, and F, respectively. Motifs A, B, C, and D are located in the palm domain, whereas motif $\mathrm{E}$ is in the palm domain, and motif $F$, in the fingers domain. The crystal structure also showed that $3 \mathrm{D}^{\mathrm{pol}}(\mathrm{RdRp})$ is a specific $\mathrm{Mn}^{2+}$-dependent polymerase (Wu et al., 2010). 
TABLE 3 | The functions and pathways of EV-A71 non-structural proteins.

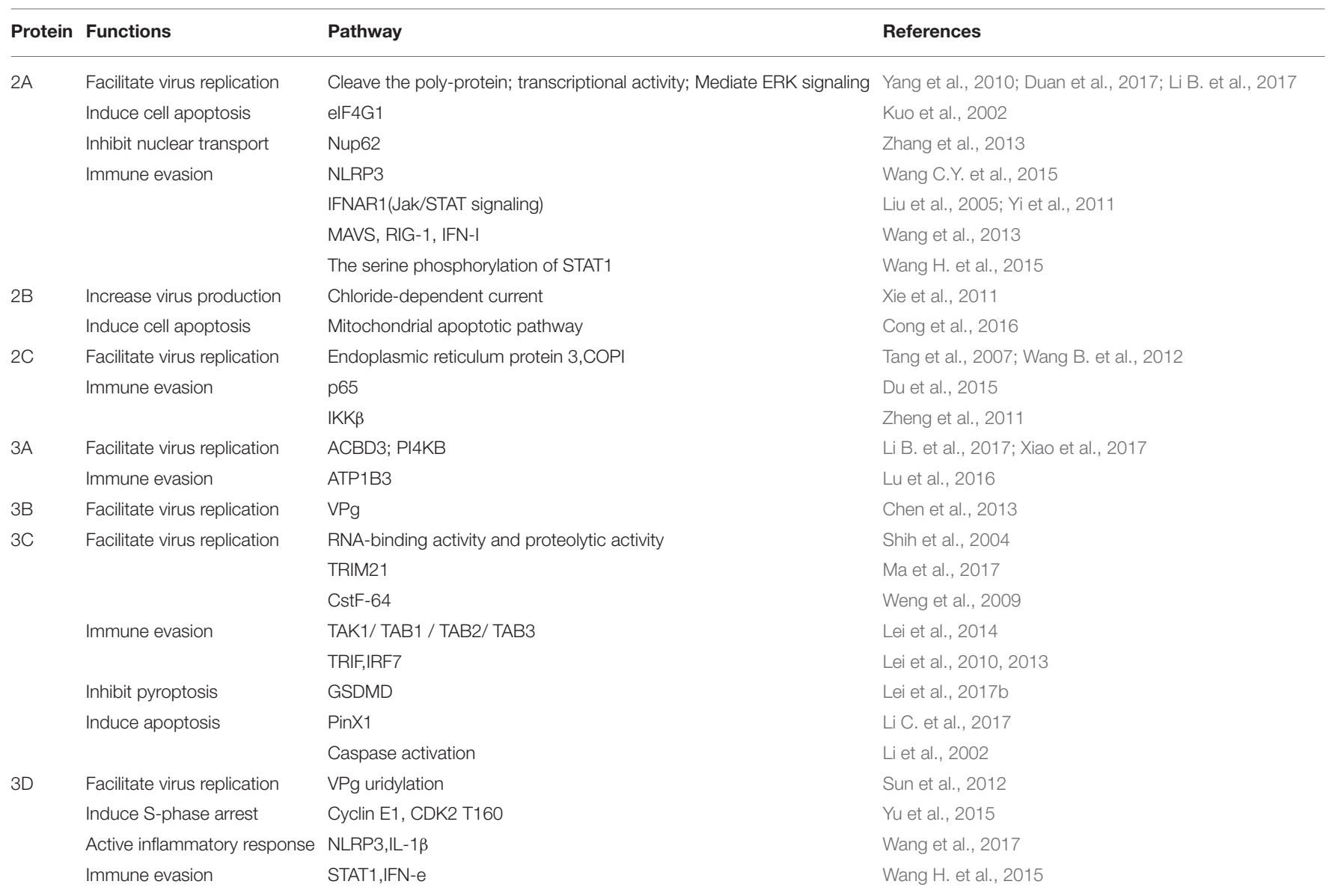

$3 \mathrm{D}^{\text {pol }}$ is responsible for RNA replication, just like RdRp. Additionally, 3D $\mathrm{D}^{\mathrm{pol}}$ is involved in VPg uridylation (Sun et al., 2012). The site-311 located at the base of the palm domain of $3 \mathrm{D}$ is a VPg-binding site, which stabilizes the VPg molecule. Liu et al. demonstrated that $3 \mathrm{D}^{\text {pol }}$ is modified by SUMO1 , both during infection and in vitro. More importantly, increasing the level of SUMO-1 in EV-A71-infected cells augmented the SUMOylation and ubiquitination levels of $3 \mathrm{D}^{\mathrm{pol}}$, leading to enhanced replication of EV-A71 (Liu et al., 2016). $\mathrm{Yu}$ et al. found that $3 \mathrm{D}^{\mathrm{pol}}$ induces the modulation of the expression profile of S-phase control proteins, a function that is consistent with its role in arresting $S$ phase. The study suggested that $3 \mathrm{D}^{\mathrm{pol}}$ is primarily responsible for $S$ phase arrest caused by EV-A71 (Yu et al., 2015). Moreover, EVA71 $3 \mathrm{D}^{\text {pol }}$ was found to stimulate the activation of NLRP3 inflammasome and the release of IL- $1 \beta$ through direct binding to NLRP3. 3D interacts with NLRP3 to facilitate the assembly of inflammasome complex by forming a 3D-NLRP3-ASC (the apoptosis-associated speck-like protein possessing a caspaserecruiting domain) ring-like structure, resulting in the activation of IL-1 $\beta$. These findings demonstrate that $3 \mathrm{D}^{\text {pol }}$ plays an important role in the activation of inflammatory response (Wang et al., 2017). 3D pol may also contribute to evasion of innate immunity. $3 \mathrm{D}^{\mathrm{pol}}$ attenuated IFN- $\gamma$ signaling accompanied by a decrease in STAT1 expression, without interfering with the expression of IFN- $\gamma$ receptor (Wang L. C. et al., 2015). Some medicines targeting 3D pol , such as baicalin (Li et al., 2015) and aurintricarboxylic acid (Hung et al., 2010), exhibit potent antiviral effect.

The primary functions and related pathways of EV-A71 nonstructural proteins are shown in Table 3.

\section{CONCLUSION}

EV-A71 has four different structural proteins and seven non-structural proteins. VP1-VP4 forms the icosahedral capsid of EV-A71. They are mainly involved in receptor binding, and contain neutralizing epitopes. Some vaccines targeting VP1-VP4 have been investigated. The seven nonstructural proteins play different roles in processes such as viral replication, viral pathogenesis, and immune evasion. The primary functions of EV71 proteins are listed in Table 1. Although some functions of EV-A71 proteins have been discovered, thorough knowledge about these proteins is still lacking. Given that EV-A71 infection has emerged as a significant global concern, affecting the Asia-Pacific region in particular, development of an effective vaccine and therapeutic approach might be the best way to control this 
infection. Further detailed study of EV-A71 proteins will ultimately be useful for developing new vaccines and therapeutic agents.

\section{AUTHOR CONTRIBUTIONS}

JY, LS, JW, XZ, JG, JC conceived of the work and discussed the content. YJ drafted the manuscript, and then LS, JW, XZ, JG, JC

\section{REFERENCES}

Aw-Yong, K. L., Sam, I. C., Koh, M. T., and Chan, Y. F. (2016). Immunodominant IgM and IgG Epitopes Recognized by Antibodies Induced in Enterovirus A71Associated Hand, Foot and Mouth Disease Patients. PLoS One 11:e165659. doi: 10.1371/journal.pone.0165659

Bedard, K. M., and Semler, B. L. (2004). Regulation of picornavirus gene expression. Microbes Infect. 6, 702-713. doi: 10.1016/j.micinf.2004.03.001

Brown, B. A., Oberste, M. S., Alexander, J. P. Jr., Kennett, M. L., and Pallansch, M. A. (1999). Molecular epidemiology and evolution of enterovirus 71 strains isolated from 1970 to 1998. J. Virol. 73, 9969-9975.

Cao, Z., Ding, Y., Ke, Z., Cao, L., Li, N., Ding, G., et al. (2016). Luteoloside acts as 3C protease inhibitor of enterovirus 71 in vitro. PLoS ONE 11:e148693. doi: 10.1371/journal.pone.0148693

Chan, L. G., Parashar, U. D., Lye, M. S., Ong, F. G., Zaki, S. R., Alexander, J. P., et al. (2000). Deaths of children during an outbreak of hand, foot, and mouth disease in sarawak, malaysia: clinical and pathological characteristics of the disease. for the outbreak study group. Clin. Infect. Dis. 31, 678-683. doi: 10.1086/ 314032

Chen, C., Wang, Y., Shan, C., Sun, Y., Xu, P., Zhou, H., et al. (2013). Crystal structure of enterovirus 71 RNA-dependent RNA polymerase complexed with its protein primer VPg: implication for a trans mechanism of VPg uridylylation. J. Virol. 87, 5755-5768. doi: 10.1128/JVI.02733-12

Chen, S. C., Chang, L. Y., Wang, Y. W., Chen, Y. C., Weng, K. F., Shih, S. R., et al. (2011). Sumoylation-promoted enterovirus 71 3C degradation correlates with a reduction in viral replication and cell apoptosis. J. Biol. Chem. 286, 31373-31384. doi: 10.1074/jbc.M111.254896

Chen, Y. C., Yu, C. K., Wang, Y. F., Liu, C. C., Su, I. J., and Lei, H. Y. (2004). A murine oral enterovirus 71 infection model with central nervous system involvement. J. Gen. Virol. 85, 69-77. doi: 10.1099/vir.0.19423-0

Chow, M., Newman, J. F., Filman, D., Hogle, J. M., Rowlands, D. J., and Brown, F. (1987). Myristylation of picornavirus capsid protein VP4 and its structural significance. Nature 327, 482-486. doi: 10.1038/327482a0

Chu, P. Y., Lin, K. H., Hwang, K. P., Chou, L. C., Wang, C. F., Shih, S. R., et al. (2001). Molecular epidemiology of enterovirus 71 in Taiwan. Arch. Virol. 146, 589-600. doi: 10.1007/s007050170164

Cong, H., Du, N., Yang, Y., Song, L., Zhang, W., and Tien, P. (2016). Enterovirus 71 $2 \mathrm{~B}$ Induces cell apoptosis by directly inducing the conformational activation of the proapoptotic protein bax. J. Virol. 90, 9862-9877. doi: 10.1128/JVI.01499-16

Cordey, S., Petty, T. J., Schibler, M., Martinez, Y., Gerlach, D., van Belle, S., et al. (2012). Identification of site-specific adaptations conferring increased neural cell tropism during human enterovirus 71 infection. PLoS Pathog. 8:e1002826. doi: 10.1371/journal.ppat.1002826

Cui, S., Wang, J., Fan, T., Qin, B., Guo, L., Lei, X., et al. (2011). Crystal structure of human enterovirus 71 3C protease. J. Mol. Biol. 408, 449-461. doi: 10.1016/j.jmb.2011.03.007

Deng, Y. Q., Ma, J., Xu, L. J., Li, Y. X., Zhao, H., Han, J. F., et al. (2015). Generation and characterization of a protective mouse monoclonal antibody against human enterovirus 71. Appl. Microbiol. Biotechnol. 99, 7663-7671. doi: 10.1007/s00253-015-6652-8

Du, H., Yin, P., Yang, X., Zhang, L., Jin, Q., and Zhu, G. (2015)., Enterovirus 71 2C protein inhibits NF-kappaB activation by binding to RelA(p65). Sci. Rep. 5:14302. doi: $10.1038 /$ srep 14302

Duan, H., Zhu, M., Xiong, Q., Wang, Y., Xu, C., Sun, J., et al. (2017). Regulation of enterovirus $2 \mathrm{~A}$ protease-associated viral IRES activities by the cell's ERK were responsible for revising it. LM critically reviewed, edited, and finalized the manuscript for submission.

\section{FUNDING}

This work was supported by National Natural Science Foundation of China (Grant No.81601751), Jiangsu Province Medical Talents Program (Grant No.QNRC2016453), and Jiangsu Province “333” Project (Grant No.BRA2017144).

signaling cascade: implicating ERK as an efficiently antiviral target. Antiviral Res. 143, 13-21. doi: 10.1016/j.antiviral.2017.03.018

Duy, N. N., Huong, L. T. T., Ravel, P., Huong, L. T. S., Dwivedi, A., Sessions, O. M., et al. (2017). Valine/isoleucine variants drive selective pressure in the VP1 sequence of EV-A71 enteroviruses. BMC Infect Dis. 17:4. doi: 10.1186/s12879-017-2427-4

Foo, D. G., Alonso, S., Phoon, M. C., Ramachandran, N. P., Chow, V. T., and Poh, C. L. (2007). Identification of neutralizing linear epitopes from the VP1 capsid protein of enterovirus 71 using synthetic peptides. Virus Res. 125, 61-68. doi: 10.1016/j.virusres.2006.12.005

Foo, D. G., Macary, P. A., Alonso, S., and Poh, C. L. (2008). Identification of human $\mathrm{CD}^{+}{ }^{+} \mathrm{T}$-cell epitopes on the VP1 capsid protein of enterovirus 71 . Viral. Immunol. 21, 215-224. doi: 10.1089/vim.2007.0089

Gao, F., Wang, Y. P., Mao, Q. Y., Yao, X., Liu, S., Li, F. X., et al. (2012). Enterovirus 71 viral capsid protein linear epitopes: identification and characterization. Virol. J. 9:26. doi: 10.1186/1743-422X-9-26

Gao, M., Duan, H., Liu, J., Zhang, H., Wang, X., Zhu, M., et al. (2014). The multi-targeted kinase inhibitor sorafenib inhibits enterovirus 71 replication by regulating IRES-dependent translation of viral proteins. Antiviral Res. 106, 80-85. doi: 10.1016/j.antiviral.2014.03.009

Gao, Q., Yuan, S., Zhang, C., Wang, Y., He, G., Zhang, S., et al. (2015). Discovery of itraconazole with broad-spectrum in vitro antienterovirus activity that targets non-structural protein 3A. Antimicrob. Agents Chemother 59, 2654-2665. doi: 10.1128/AAC.05108-14

Guan, H., Tian, J., Qin, B., Wojdyla, J. A., Wang, B., Zhao, Z., et al. (2017). Crystal structure of 2C helicase from enterovirus 71. Sci. Adv. 3:e1602573. doi: 10.1126/sciadv.1602573

Han, Y., Wang, L., Cui, J., Song, Y., Luo, Z., Chen, J., et al. (2016). SIRT1 inhibits EV71 genome replication and RNA translation by interfering with the viral polymerase and 5'UTR RNA. J. Cell Sci. 129, 4534-4547. doi: $10.1242 /$ jcs. 193698

Ho, M., Chen, E. R., Hsu, K. H., Twu, S. J., Chen, K. T., Tsai, S. F., et al. (1999). An epidemic of enterovirus 71 infection in Taiwan. Taiwan enterovirus epidemic working group. N. Engl. J. Med. 341, 929-935. doi: 10.1056/NEJM199909233411301

Hu, D. D., Mai, J. N., He, L. Y., Li, P. Q., Chen, W. X., Yan, J. J., et al. (2017). Glucocorticoids prevent enterovirus 71 capsid protein VP1 induced calreticulin surface exposure by alleviating neuronal ER stress. Neurotox Res. 31, 204-217. doi: 10.1007/s12640-016-9670-0

Huang, S. W., Wang, Y. F., Yu, C. K., Su, I. J., and Wang, J. R. (2012). Mutations in VP2 and VP1 capsid proteins increase infectivity and mouse lethality of enterovirus 71 by virus binding and RNA accumulation enhancement. Virology 422, 132-143. doi: 10.1016/j.virol.2011.10.015

Hung, H. C., Chen, T. C., Fang, M. Y., Yen, K. J., Shih, S. R., Hsu, J. T., et al. (2010). Inhibition of enterovirus 71 replication and the viral 3D polymerase by aurintricarboxylic acid. J. Antimicrob. Chemother 65, 676-683. doi: 10.1093/jac/dkp502

Ishiko, H., Shimada, Y., Yonaha, M., Hashimoto, O., Hayashi, A., Sakae, K., et al. (2002). Molecular diagnosis of human enteroviruses by phylogenybased classification by use of the VP4 sequence. J. Infect Dis. 185, 744-754. doi: $10.1086 / 339298$

Jia, Q., Ng, Q., Chin, W., Meng, T., Chow, V. T. K., Wang, C. I., et al. (2017). Effective in vivo therapeutic IgG antibody against VP3 of enterovirus 71 with receptor-competing activity. Sci. Rep. 7:46402. doi: 10.1038/srep 46402 
Kataoka, C., Suzuki, T., Kotani, O., Iwata-Yoshikawa, N., Nagata, N., Ami, Y., et al. (2015). The role of VP1 amino acid residue 145 of enterovirus 71 in viral fitness and pathogenesis in a cynomolgus monkey model. PLoS Pathog. 11:e1005033. doi: 10.1371/journal.ppat.1005033

Kiener, T. K., Jia, Q., Lim, X. F., He, F., Meng, T., Chow, V. T., et al. (2012). Characterization and specificity of the linear epitope of the enterovirus 71 VP2 protein. Virol. J. 9:55. doi: 10.1186/1743-422X-9-55

Kiener, T. K., Jia, Q., Meng, T., Chow, V. T., and Kwang, J. (2014). A novel universal neutralizing monoclonal antibody against enterovirus 71 that targets the highly conserved "knob" region of VP3 protein. PLoS Negl. Trop. Dis. 8:e2895. doi: 10.1371/journal.pntd.0002895

Kiener, T. K., Premanand, B., and Kwang, J. (2013). Immune responses to baculovirus-displayed enterovirus 71 VP1 antigen. Expert Rev. Vac. 12, 357-364. doi: 10.1586/erv.13.18

Kok, C. C., Phuektes, P., Bek, E., and McMinn, P. C. (2012). Modification of the untranslated regions of human enterovirus 71 impairs growth in a cell-specific manner. J. Virol. 86, 542-552. doi: 10.1128/JVI.00069-11

Ku, Z., Ye, X., Shi, J., Wang, X., Liu, Q., and Huang, Z. (2015). Single neutralizing monoclonal antibodies targeting the VP1 GH loop of enterovirus 71 inhibit both virus attachment and internalization during viral entry. J. Virol. 89, 12084-12095. doi: 10.1128/JVI.02189-15

Kuo, R. L., Kung, S. H., Hsu, Y. Y., and Liu, W. T. (2002). Infection with enterovirus 71 or expression of its $2 \mathrm{~A}$ protease induces apoptotic cell death. J. Gen. Virol. 83, 1367-1376. doi: 10.1099/0022-1317-83-6-1367

Lei, X., Han, N., Xiao, X., Jin, Q., He, B., and Wang, J. (2014). Enterovirus 71 3C inhibits cytokine expression through cleavage of the TAK1/TAB1/TAB2/TAB3 complex. J. Virol. 88, 9830-9841. doi: 10.1128/JVI.01425-14

Lei, X., Liu, X., Ma, Y., Sun, Z., Yang, Y., Jin, Q., et al. (2010). The 3C protein of enterovirus 71 inhibits retinoid acid-inducible gene I-mediated interferon regulatory factor 3 activation and type I interferon responses. J. Virol. 84, 8051-8061. doi: 10.1128/JVI.02491-09

Lei, X., Xiao, X., Xue, Q., Jin, Q., He, B., and Wang, J. (2013). Cleavage of interferon regulatory factor 7 by enterovirus $713 \mathrm{C}$ suppresses cellular responses. J. Virol. 87, 1690-1698. doi: 10.1128/JVI.01855-12

Lei, X., Xiao, X., Zhang, Z., Ma, Y., Qi, J., Wu, C., et al. (2017a). The Golgi protein ACBD3 facilitates enterovirus 71 replication by interacting with 3A. Sci. Rep. 7:44592. doi: 10.1038/srep44592

Lei, X., Zhang, Z., Xiao, X., Qi, J., He, B., and Wang, J. (2017b). Enterovirus 71 inhibits pyroptosis through cleavage of gasdermin D. J. Virol. 91:e01069-17. doi: 10.1128/JVI.01069-17

Li, B., Yue, Y., Zhang, Y., Yuan, Z., Li, P., Song, N., et al. (2017). A novel enterovirus 71 (EV71) virulence determinant: the 69th residue of 3C protease modulates pathogenicity. Front. Cell Infect. Microbiol. 7:26. doi: 10.3389/fcimb.2017. 00026

Li, C., Qiao, Q., Hao, S. B., Dong, Z., Zhao, L., Ji, J., et al. (2017). Non-structural protein $2 \mathrm{~A}$ modulates replication and virulence of enterovirus 71. Virus Res. 244, 262-269. doi: 10.1016/j.virusres.2017.11.023

Li, J., Yao, Y., Chen, Y., Xu, X., Lin, Y., Yang, Z., et al. (2017). Enterovirus 71 3C promotes apoptosis through cleavage of PinX1, a telomere binding protein. J. Virol. 91:e02016-16. doi: 10.1128/JVI.02016-16

Li, M. L., Hsu, T. A., Chen, T. C., Chang, S. C., Lee, J. C., Chen, C. C., et al. (2002). The $3 \mathrm{C}$ protease activity of enterovirus 71 induces human neural cell apoptosis. Virology 293, 386-395. doi: 10.1006/viro.2001.1310

Li, X., Liu, Y., Wu, T., Jin, Y., Cheng, J., Wan, C., et al. (2015). The antiviral effect of baicalin on enterovirus 71 in vitro. Viruses 7, 4756-4771. doi: 10.3390/v7082841

Lim, X. F., Jia, Q., Chow, V. T., and Kwang, J. (2013). Characterization of a novel monoclonal antibody reactive against the $\mathrm{N}$-terminal region of enterovirus 71 VP1 capsid protein. J .Virol. Methods 188, 76-82. doi: 10.1016/j.jviromet.2012.11.038

Lin, J. Y., Chen, T. C., Weng, K. F., Chang, S. C., Chen, L. L., and Shih, S. R. (2009a). Viral and host proteins involved in picornavirus life cycle. J. Biomed. Sci. 16:103. doi: 10.1186/1423-0127-16-103

Lin, J. Y., Li, M. L., and Shih, S. R. (2009b). Far upstream element binding protein 2 interacts with enterovirus 71 internal ribosomal entry site and negatively regulates viral translation. Nucleic Acids Res. 37, 47-59. doi: 10.1093/nar/gkn901

Liu, C. C., Chou, A. H., Lien, S. P., Lin, H. Y., Liu, S. J., Chang, J. Y., et al. (2011). Identification and characterization of a cross-neutralization epitope of Enterovirus 71. Vaccine 29, 4362-4372. doi: 10.1016/j.vaccine.2011. 04.010

Liu, M. L., Lee, Y. P., Wang, Y. F., Lei, H. Y., Liu, C. C., Wang, S. M., et al. (2005). Type I interferons protect mice against enterovirus 71 infection. J. Gen. Virol. 86, 3263-3269. doi: 10.1099/vir.0.81195-0

Liu, Y., Zheng, Z., Shu, B., Meng, J., Zhang, Y., Zheng, C., et al. (2016). SUMO modification stabilizes enterovirus 71 polymerase $3 \mathrm{D}$ to facilitate viral replication. J. Virol. 90, 10472-10485. doi: 10.1128/JVI.01756-16

Lu, Y., Hou, H., Wang, F., Qiao, L., Wang, X., Yu, J., et al. (2016). ATP1B3: a virusinduced host factor against EV71 replication by up-regulating the production of type-I interferons. Virology 496, 28-34. doi: 10.1016/j.virol.2016.05.013

Lyu, K., Ding, J., Han, J. F., Zhang, Y., Wu, X. Y., He, Y. L., et al. (2014). Human enterovirus 71 uncoating captured at atomic resolution. J. Virol. 88, 3114-3126. doi: 10.1128/JVI.03029-13

Ma, G. H., Ye, Y., Zhang, D., Xu, X., Si, P., Peng, J. L., et al. (2016). Identification and biochemical characterization of DC07090 as a novel potent small molecule inhibitor against human enterovirus $713 \mathrm{C}$ protease by structure-based virtual screening. Eur. J. Med. Chem. 124, 981-991. doi: 10.1016/j.ejmech.2016.10.019

Ma, H. Y., Lu, C. Y., Tsao, K. C., Shih, H. M., Cheng, A. L., Huang, L. M., et al (2017). Association of EV71 3C polymorphisms with clinical severity. J. Microbiol. Immunol. Infect. doi: 10.1016/j.jmii.2016.12.006. [Epub ahead of print].

Mu, Z., Wang, B., Zhang, X., Gao, X., Qin, B., Zhao, Z., et al. (2013). Crystal structure of $2 \mathrm{~A}$ proteinase from hand, foot and mouth disease virus. J. Mol. Biol. 425, 4530-4543. doi: 10.1016/j.jmb.2013.08.016

Nishimura, Y., Lee, H., Hafenstein, S., Kataoka, C., Wakita, T., Bergelson, J. M., et al. (2013). Enterovirus 71 binding to PSGL-1 on leukocytes: VP1-145 acts as a molecular switch to control receptor interaction. PLoS Pathog. 9:e1003511. doi: 10.1371/journal.ppat.1003511

Nishimura, Y., Shimojima, M., Tano, Y., Miyamura, T., Wakita, T., and Shimizu, H. (2009). Human P-selectin glycoprotein ligand-1 is a functional receptor for enterovirus 71. Nat. Med. 15, 794-797. doi: 10.1038/nm.1961

Ooi, M. H., Wong, S. C., Lewthwaite, P., Cardosa, M. J., and Solomon, T. (2010). Clinical features, diagnosis, and management of enterovirus 71. Lancet Neurol. 9, 1097-1105. doi: 10.,1016/S1474-4422(10)70209-X

Plevka, P., Perera, R., Cardosa, J., Kuhn, R. J., and Rossmann, M. G. (2012). Crystal structure of human enterovirus 71. Science 336, 1274. doi: $10.1126 /$ science. 1218713

Rossmann, M. G. (1994). Viral cell recognition and entry. Protein Sci. 3, 1712-1725. doi: $10.1002 /$ pro. 5560031010

Rossmann, M. G., He, Y., and Kuhn, R. J. (2002). Picornavirus-receptor interactions. Trends Microbiol. 10, 324-331. doi: 10.1016/S0966842X(02)02383-1

Schmidt, N. J., Lennette, E. H., and Ho, H. H. (1974). An apparently new enterovirus isolated from patients with disease of the central nervous system. J. Infect. Dis. 129, 304-309. doi: 10.1093/infdis/129.3.304

Shih, S. R., Chiang, C., Chen, T. C., Wu, C. N., Hsu, J. T., Lee, J. C., et al. (2004). Mutations at KFRDI and VGK domains of enterovirus 71 3C protease affect its RNA binding and proteolytic activities. J. Biomed. Sci. 11, 239-248. doi: 10.1007/BF02256567

Shih, S. R., Stollar, V., and Li, M. L. (2011). Host Factors in enterovirus 71 replication. J. Virol. 85, 9658-9666. doi: 10.1128/JVI.05063-11

Shimizu, H., Utama, A., Onnimala, N., Li, C., Li-Bi, Z., Yu-Jie, M., et al. (2004). Molecular epidemiology of enterovirus 71 infection in the Western Pacific Region. Pediatr Int. 46, 231-235. doi: 10.1046/j.1442-200x.2004.01868.x

Shingler, K. L., Cifuente, J. O., Ashley, R. E., Makhov, A. M., Conway, J. F., and Hafenstein, S. (2015). The enterovirus 71 procapsid binds neutralizing antibodies and rescues virus infection in vitro. J. Virol. 89, 1900-1908. doi: 10.1128/JVI.03098-14

Shingler, K. L., Yoder, J. L., Carnegie, M. S., Ashley, R. E., Makhov, A. M., Conway, J. F., et al. (2013). The enterovirus 71 A-particle forms a gateway to allow genome release: a cryoEM study of picornavirus uncoating. PLoS Pathog. 9:e1003240. doi: 10.1371/journal.ppat.1003240

Solomon, T., Lewthwaite, P., Perera, D., Cardosa, M. J., McMinn, P., and Ooi, M. H. (2010). Virology, epidemiology, pathogenesis, and control of enterovirus 71 . Lancet Infect. Dis. 10, 778-790. doi: 10.,1016/S1473-3099(10)70194-8

Song, Y., Cheng, X., Yang, X., Zhao, R., Wang, P., Han, Y., et al. (2015). Early growth response-1 facilitates enterovirus 71 replication by direct 
binding to the viral genome RNA. Int. J. Biochem. Cell Biol. 62, 36-46. doi: 10.1016/j.biocel.2015.02.012

Su, P. Y., Liu, Y. T., Chang, H. Y., Huang, S. W., Wang, Y. F., Yu, C. K., et al. (2012). Cell surface sialylation affects binding of enterovirus 71 to rhabdomyosarcoma and neuroblastoma cells. BMC Microbiol. 12:162. doi: $10.1186 / 1471-2180-12-162$

Sun, L. M., Zheng, H. Y., Zheng, H. Z., Guo, X., He, J. F., Guan, D. W., et al. (2011). An enterovirus 71 epidemic in Guangdong province of China, 2008: epidemiological, clinical, and virogenic manifestations. Jpn. J. Infect. Dis. 64, 13-18.

Sun, Y., Wang, Y., Shan, C., Chen, C., Xu, P., Song, M., et al. (2012). Enterovirus 71 VPg uridylation uses a two-molecular mechanism of 3D polymerase. J. Virol. 86, 13662-13671. doi: 10.1128/JVI.01712-12

Tan, C. W., Poh, C. L., Sam, I. C., and Chan, Y. F. (2013). Enterovirus 71 uses cell surface heparan sulfate glycosaminoglycan as an attachment receptor. J. Virol. 87, 611-620. doi: 10.1128/JVI.02226-12

Tan, X., Huang, X., Zhu, S., Chen, H., Yu, Q., Wang, H., et al. (2011). The persistent circulation of enterovirus 71 in People's Republic of China: causing emerging nationwide epidemics since 2008. PLOS ONE 6:e25662. doi: 10.1371/journal.pone.0025662

Tang, W. F., Yang, S. Y., Wu, B. W., Jheng, J. R., Chen, Y. L., Shih, C. H., et al. (2007). Reticulon 3 binds the $2 \mathrm{C}$ protein of enterovirus 71 and is required for viral replication. J. Biol. Chem. 282, 5888-5898. doi: 10.1074/jbc.M6111 45200

Thompson, S. R., and Sarnow, P. (2003). Enterovirus 71 contains a type I IRES element that functions when eukaryotic initiation factor eIF4G is cleaved. Virology 315, 259-266. doi: 10.1016/S0042-6822(03)00544-0

Van Tu, P., Thao, N. T. T., Perera, D., Truong, K. H., Tien, N. T. K., Thuong, T. C., et al. (2007). Epidemiologic and virologic investigation of hand, foot, and mouth disease, southern Vietnam, (2005). Emerg. Infect. Dis. 13, 1733-1741. doi: 10.3201/eid1311.070632

Wang, B., Xi, X., Lei, X., Zhang, X., Cui, S., Wang, J., et al. (2013). Enterovirus 71 Protease 2A(pro) targets MAVS to inhibit anti-viral type I interferon responses. PLoS Pathog. 9:e1006243. doi: 10.1371/journal.ppat.1006243

Wang, B., Zhang, H., Zhu, M., Luo, Z., and Peng, Y. (2012). MEK1-ERKs signal cascade is required for the replication of enterovirus 71 (EV71). Antiviral Res. 93, 110-117. doi: 10.1016/j.antiviral.2011.11.001

Wang, C. Y., Huang, A. C., Hour, M. J., Huang, S. H., Kung, S. H., Chen, C. H., et al. (2015). Antiviral potential of a novel compound CW-33 against enterovirus A71 via inhibition of viral 2A protease. Viruses 7, 3155-3171. doi: 10.3390/v7062764

Wang, H., Lei, X., Xiao, X., Yang, C., Lu, W., Huang, Z., et al. (2015). Reciprocal regulation between enterovirus 71 and the NLRP3 Inflammasome. Cell Rep. 12, 42-48. doi: 10.1016/j.celrep.2015.05.047

Wang, J., Bakkers, J. M., Galama, J. M., Bruins Slot, H. J., Pilipenko, E. V., Agol, V. I., et al. (1999). Structural requirements of the higher order RNA kissing element in the enteroviral 3'UTR. Nucleic Acids Res. 27, 485-490. doi: 10.1093/nar/27.2.485

Wang, J., Wu, Z., and Jin, Q. (2012). COPI is required for enterovirus 71 replication. PLoS ONE 7:e0038035. doi: 10.1371/journal.pone.0038035

Wang, L. C., Chen, S. O., Chang, S. P., Lee, Y. P., Yu, C. K., Chen, C. L., et al. (2015). Enterovirus 71 proteins $2 \mathrm{~A}$ and $3 \mathrm{D}$ antagonize the antiviral activity of gamma interferon via signaling attenuation. J. Virol. 89, 7028-7037. doi: 10.1128/JVI.00205-15

Wang, W., Xiao, F., Wan, P., Pan, P., Zhang, Y., Liu, F., et al. (2017). EV71 3D protein binds with NLRP3 and enhances the assembly of inflammasome complex. PLoS Pathog. 13:e1006123. doi: 10.1371/journal.ppat.1006123

Wei, R., Yang, C., Zeng, M., Terry, F., Zhu, K., Altmeyer, R., et al. (2012). A dominant EV71-specific CD4+ T cell epitope is highly conserved among human enteroviruses. PLoS One 7:e51957. doi: 10.1371/journal.pone.0051957

Weng, K. F., Li, M. L., Hung, C. T., and Shih, S. R. (2009). Enterovirus 71 3C protease cleaves a novel target CstF-64 and inhibits cellular polyadenylation. PLoS Pathog. 5:e1000593. doi: 10.1371/journal.ppat.1000593

Wimmer, E., Kuhn, R. J., Pincus, S., Yang, C. F., Toyoda, H., Nicklin, M. J., et al. (1987). Molecular events leading to picornavirus genome replication. J. Cell Sci. Suppl. 7, 251-276. doi: 10.1242/jcs.1987.Supplement7.18

Wu, C., Cai, Q., Chen, C., Li, N., Peng, X., Cai, Y., et al. (2013). Structures ofEnterovirus 713C proteinase (strain E2004104-TW-CDC) and its complex with rupintrivir. Acta Crystallogr. D Biol. Crystallogr. 69, 866-871. doi: $10.1107 /$ S0907444913002862

Wu, J. S., Zhao, N., Pan, H., Wang, C. M., Wu, B., Zhang, H. M., et al. (2013). Patterns of polymorphism and divergence in the VP1 gene of enterovirus 71 circulating in the Asia-Pacific region between 1994 and 2013. J. Virol. Methods 193, 713-728. doi: 10.1016/j.jviromet.2013.07.051

Wu, S., Wang, Y., Lin, L., Si, X., Wang, T., Zhong, X., et al. (2014). Protease 2A induces stress granule formation during coxsackievirus B3 and enterovirus 71 infections. Virol. J. 11, 192. doi: 10.1186/s12985-014-0192-1

Wu, W. H., Kuo, T. C., Lin, Y. T., Huang, S. W., Liu, H. F., Wang, J., et al. (2013). Molecular epidemiology of enterovirus 71 infection in the central region of Taiwan from 2002 to 2012. PLOS ONE. 8:e83711. doi: 10.1371/journal.pone.0083711

Wu, Y., Lou, Z., Miao, Y., Yu, Y., Dong, H., Peng, W., et al. (2010). Structures of EV71 RNA-dependent RNA polymerase in complex with substrate and analogue provide a drug target against the hand-foot-and-mouth disease pandemic in China. Protein Cell 1, 491-500. doi: 10.1007/s13238-010-0061-7

Xiao, X., Lei, X., Zhang, Z., Ma, Y., Qi, J., Wu, C., et al. (2017). Enterovirus 3A facilitates viral replication by promoting Phosphatidylinositol 4-Kinase IIIß-ACBD3 interaction. J. Virol. 91:e00791-17. doi: 10.1128/JVI.00791-17

Xie, S., Wang, K., Yu, W., Lu, W., Xu, K., Wang, J., et al. (2011). DIDS blocks a chloride-dependent current that is mediated by the $2 \mathrm{~B}$ protein of enterovirus 71. Cell Res. 21, 1271-1275. doi: 10.1038/cr.2011.112

$\mathrm{Xu}$, J., and Zhang, C. (2016). Human IgG Fc promotes expression, secretion and immunogenicity of enterovirus 71 VP1 protein. J. Biomed. Res. 30, 209-216. doi: 10.7555/JBR.30.20140157

Xu, L., He, D., Li, Z., Zheng, J., Yang, L., Yu, M., et al. (2014). Protection against lethal enterovirus 71 challenge in mice by a recombinant vaccine candidate containing a broadly cross-neutralizing epitope within the VP2 EF loop. Theranostics 4, 498-513. doi: 10.7150/thno.7457

Xu, L., He, D., Yang, L., Li, Z., Ye, X., Yu, H., et al. (2015). A broadly cross-protective vaccine presenting the neighboring epitopes within the VP1 GH Loop and VP2 EF loop of Enterovirus 71. Sci Rep. 5:12973. doi: $10.1038 /$ srep 12973

Yamayoshi, S., Yamashita, Y., Li, J., Hanagata, N., Minowa, T., Takemura, T., et al. (2009). Scavenger receptor B2 is a cellular receptor for enterovirus 71. Nat. Med. 15, 798-801. doi: 10.1038/nm.1992

Yang, B., Chuang, H., and Yang, K. D. (2009). Sialylated glycans as receptor and inhibitor of enterovirus 71 infection to DLD-1 intestinal cells. Virol. J. 6:141. doi: 10.1186/1743-422X-6-141

Yang, C. H., Li, H. C., Jiang, J. G., Hsu, C. F., Wang, Y. J., Lai, M. J., et al. (2010). Enterovirus type $712 \mathrm{~A}$ protease functions as a transcriptional activator in yeast. J. Biomed. Sci. 17:65. doi: 10.1186/1423-0127-17-65

Yang, S. L., Chou, Y. T., Wu, C. N., and Ho, M. S. (2011). Annexin II binds to capsid protein VP1 of enterovirus 71 and enhances viral infectivity. J. Virol. 85, 11809-11820. doi: 10.1128/JVI.00297-11

Yi, E. J., Shin, J. Y., Kim, H. J., Kim, G. T., and Chang, Y. S. (2017). Enterovirus 71 infection and vaccines. Clin. Exp. Vac. Res. 6:4. doi: 10.7774/cevr.2017.6.1.4

Yi, L., He, Y., Chen, Y., Kung, H. F., and He, M. L. (2011). Potent inhibition of human enterovirus 71 replication by type I interferon subtypes. Antivir. Ther. 16, 51-58. doi: 10.3851/IMP1720

Yu, J., Zhang, L., Ren, P., Zhong, T., Li, Z., Wang, Z., et al. (2015). Enterovirus 71 mediates cell cycle arrest in $S$ phase through non-structural protein 3D. Cell Cycle 14, 425-436. doi: 10.4161/15384101.2014.980631

Yu, Z., Huang, Z., Sao, C., Huang, Y., Zhang, F., Ma, G., et al. (2013). Oral immunization of mice using Bifidobacterium longum expressing VP1 protein from enterovirus 71. Arch. Virol. 158, 1071-1077. doi: $10.1007 / \mathrm{s} 00705-012-1589-\mathrm{z}$

Zaini, Z., and McMinn, P. (2012). A single mutation in capsid protein VP1 (Q145E) of a genogroup C4 strain of human enterovirus 71 generates a mouse-virulent phenotype. J. Gen. Virol. 93, 1935-1940. doi: 10.1099/vir.0.04 3893-0

Zaini, Z., Phuektes, P., and McMinn, P. (2012). Mouse adaptation of a subgenogroup B5 strain of human enterovirus 71 is associated with a novel lysine to glutamic acid substitution at position 244 in protein VP1. Virus Res. 167, 86-96. doi: 10.1016/j.virusres.2012.04.009

Zhang, H., Song, L., Cong, H., and Tien, P. (2015). Nuclear protein Sam68 interacts with the enterovirus 71 internal ribosome entry site and positively regulates 
viral protein translation. J. Virol. 89, 10031-10043. doi: 10.1128/JVI.016 $77-15$

Zhang, J., Sun, J., Chang, Z., Zhang, W., Wang, Z., and Feng, Z. (2011). Characterization of hand, foot, and mouth disease in China between 2008 and 2009. Biomed. Environ. Sci. 24, 214-221. doi: 10.3967/0895-3988.2011. 03.002

Zhang, Y. Z., Gan, X., Song, J., Sun, P., Song, Q. Q., Li, G. Q. et al. (2013). The 2A protease of enterovirus 71 cleaves nup62 to inhibit nuclear transport. Bing Du Xue Bao 29, 421-425. doi: 10.13242/j.cnki.bingduxuebao.002412

Zhang, Y. X., Huang, Y. M., Li, Q. J., Li, X. Y., Zhou, Y. D., Guo, F., et al. (2017). A highly conserved amino acid in VP1 regulates maturation of enterovirus 71 . PLoS Pathog. 13:e1006625. doi: 10.1371/journal.ppat.1006625

Zhao, M., Bai, Y., Liu, W., Xiao, X., Huang, Y., Cen, S., et al. (2013). Immunization of $\mathrm{N}$ terminus of enterovirus $71 \mathrm{VP} 4$ elicits cross-protective antibody responses. BMC Microbiol. 13:287. doi: 10.1186/1471-2180-13-287

Zheng, Z., Li, H., Zhang, Z., Meng, J., Mao, D., Bai, B., et al. (2011). Enterovirus $712 \mathrm{C}$ protein inhibits TNF-alpha-mediated activation of NF-kappaB by suppressing IkappaB kinase beta phosphorylation. J. Immunol. 187, 2202-2212. doi: 10.4049/jimmunol.1100285

Zhu, M., Duan, H., Gao, M., Zhang, H., and Peng, Y. (2015). Both ERK1 and ERK2 are required for enterovirus 71 (EV71) efficient replication. Viruses 7, 1344-1356. doi: 10.3390/v7031344

Conflict of Interest Statement: The authors declare that the research was conducted in the absence of any commercial or financial relationships that could be construed as a potential conflict of interest.

Copyright (c) 2018 Yuan, Shen, Wu, Zou, Gu, Chen and Mao. This is an open-access article distributed under the terms of the Creative Commons Attribution License (CC BY). The use, distribution or reproduction in other forums is permitted, provided the original author(s) and the copyright owner are credited and that the original publication in this journal is cited, in accordance with accepted academic practice. No use, distribution or reproduction is permitted which does not comply with these terms. 